\title{
Development of Aeroservoelastic Analytical Models and Gust Load Alleviation Control Laws of a SensorCraft Wind-Tunnel Model Using Measured Data
}

\author{
Walter A. Silva* \\ NASA Langley Research Center, Hampton, Virginia, 23681 \\ Eric $\operatorname{Vartio}^{\dagger}$ \\ Northrop-Grumman Integrated Systems, El Segundo, California, 90245 \\ Anthony Shimko \\ Northrop-Grumman Integrated Systems, El Segundo, California, 90245 \\ Raymond G. Kvaternik ${ }^{\S}$ \\ NASA Langley Research Center, Hampton, Virginia, 23681 \\ Kenneth W. Eureף \\ NASA Langley Research Center, Hampton, Virginia, 23681 \\ Robert C. Scott" \\ NASA Langley Research Center, Hampton, Virginia, 23681
}

\begin{abstract}
Aeroservoelastic (ASE) analytical models of a SensorCraft wind-tunnel model are generated using measured data. The data was acquired during the ASE wind-tunnel test of the HiLDA (High Lift-to-Drag Active) Wing model, tested in the NASA Langley Transonic Dynamics Tunnel (TDT) in late 2004. Two time-domain system identification techniques are applied to the development of the ASE analytical models: impulse response (IR) method and the Generalized Predictive Control (GPC) method. Using measured control surface inputs (frequency sweeps) and associated sensor responses, the IR method is used to extract corresponding input/output impulse response pairs. These impulse responses are then transformed into state-space models for use in ASE analyses. Similarly, the GPC method transforms measured random control surface inputs and associated sensor responses into an AutoRegressive with eXogenous input (ARX) model. The ARX model is then used to develop the gust load alleviation (GLA) control law. For the IR method, comparison of measured with simulated responses are presented to investigate the accuracy of the ASE analytical models developed. For the GPC method, comparison of simulated open-loop and closed-loop (GLA) time histories are presented.
\end{abstract}

\footnotetext{
*Senior Research Scientist, Aeroelasticity Branch, AIAA Associate Fellow.

$\dagger$ Engineer, Vehicle Systems, AIAA Member.

${ }^{\ddagger}$ Lead Engineer, Loads and Dynamics, AIAA Member.

$\S$ Senior Research Engineer, Aeroelasticity Branch, AIAA Associate Fellow.

IResearch Engineer, Safety-Critical Avionics Systems Branch.

"Senior Research Engineer, Aeroelasticity Branch.

Copyright (c) 2006 by the American Institute of Aeronautics and Astronautics, Inc. The U.S. Government has a royalty-free license to exercise all rights under the copyright claimed herein for Governmental purposes. All other rights are reserved by the copyright owner.
} 


\section{Introduction}

The U.S. Air Force is investing a significant level of resources towards the development of feasible SensorCraft concepts. As stated by Lucia, ${ }^{1}$ the goal of the SensorCraft effort is the development of unmanned aerial vehicles equipped with advanced radar capabilities capable of sustaining 30 hours at specific altitudes and with a range of 2000 nautical miles. These mission requirements pose significant challenges to the antenna community as well as to the aerodynamics and aeroelasticity communities. In particular, due to the stringent mission requirements and potentially increased flexibility,compared to other flight vehicles, SensorCraft vehicles pose a significant challenge in the area of aeroservoelastic (ASE) analysis and design.

Air Force-funded programs seeking to understand these ASE challenges are underway. These programs include wind-tunnel testing of aeroelastic and ASE models. One of these programs, reported by Vartio, ${ }^{2}$ is the ASE wind-tunnel testing of the HiLDA (High Lift-to-Drag Active) Wing wind-tunnel model in order to evaluate various gust load alleviation (GLA) concepts. The HiLDA Wing wind-tunnel model was tested in the Langley Transonic Dynamics Tunnel (TDT). Several GLA concepts were implemented and validated during the ASE testing. These GLA concepts were designed using ASE analytical models generated from linear analytical methods.

During ASE testing, an anomalous unstable ASE event was encountered that consisted of a nonlinear coupling that included the wind-tunnel model's first in-plane bending (fore-aft) mode and first out-of-plane (conventional) bending mode. This unstable ASE event was not predicted using standard linear methods. A primary goal of this investigation is to see if the ASE models generated using measured data include a first-order effect of the nonlinearities exhibited during the wind-tunnel test. If the accuracy of ASE models can be improved (enhanced) by the inclusion of additional measured information, this may enable the design of improved control laws. The two methods that are investigated in the present paper are the Impulse Response (IR) method and the Generalized Predictive Control (GPC) method.

\section{Description of HiLDA Wind-Tunnel Model}

A semispan model of a SensorCraft concept wing was tested in the NASA Langley Transonic Dynamics Tunnel (TDT). The model consists of a spar shaped to reflect thestructural bending characteristic of a full-scale concept wing. Masses are placed on the spar to achieve the appropriate mass distribution and aerodynamic shells cover the spar. The model is eleven feet long and was attached to the wall of the TDT test section. The model was mounted on a balance in order to measure pitching moment and lift at the center of gravity. The model has four evenly spaced trailing edge control surfaces and one leading edge control surface on the outboard portion of the wing. The wind-tunnel model is instrumented with accelerometers along the spar, strain gauges at the root and mid-spar, a rate gyro at the wing tip, a gust sensor vane in front of the wing, and a balance at the tunnel attachment point. A layout of the HiLDA model and associated instrumentation is presented as Figure 1.

The accelerometers, strain gauges and rate gyro allow the control system to sense the bending modes and the structural stresses. A gust sensor vane was placed in front of the model during portions of the test to allow lead gust information to be fed into the controller. A goal of this test was to control the first and second bending modes of the wing, pictured in Figure 2, while controlling pitch moment at the center of gravity.

The model was excited by harmonic gusts generated by the TDT flow oscillation vanes that are mounted to the tunnel sidewalls immediately upstream of the test section. Figure 3 is a schematic of the HiLDA Wing semispan wind-tunnel model in the TDT as it encounters sinusoidal gusts generated by the flow oscillation vanes.

\section{Test Setup and Conditions}

The target test condition was 70 psf dynamic pressure at a Mach number of 0.3 in the R134a test medium. This condition was established in order to get a relevant flight condition Reynolds number. Some preliminary testing was performed at $30 \mathrm{psf}$ in air in order to troubleshoot the model installation and associated systems. A photograph of the HiLDA wind-tunnel model installed in the TDT and the TDT ow oscillation vanes is presented in Figure 4. Data was recorded at a sampling frequency of $500 \mathrm{~Hz}$. 


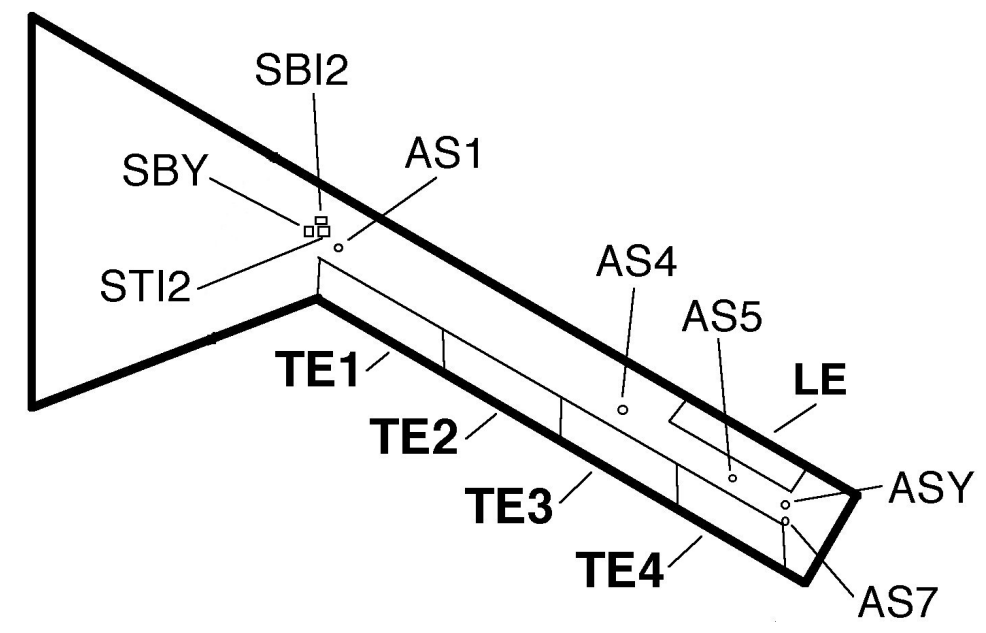

Figure 1. Partial instrumentation and control surface layout for the HiLDA Wing wind-tunnel model. SBI2: Vertical Bending Strain Gauge; SBY: Fore-and-Aft Bending Strain Gauge; STI2: Torsion Strain Gauge; AS1, AS4, AS5, AS7, and ASY: accelerometers.
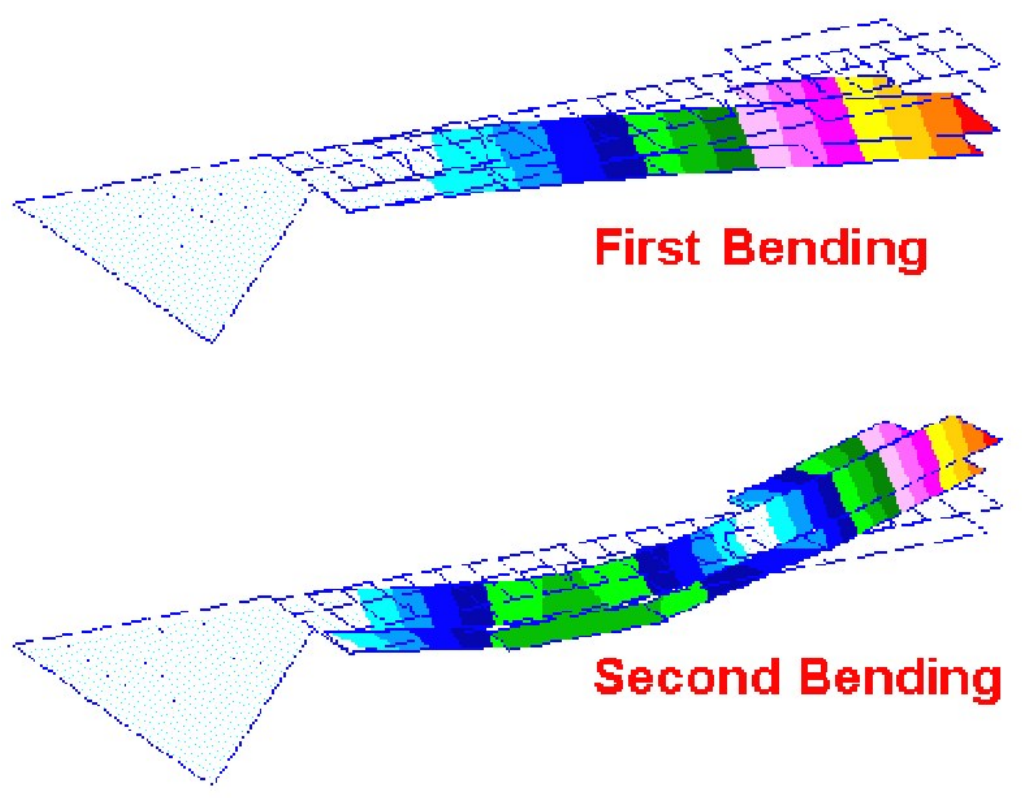

Figure 2. First and second bending modes of the HiLDA wind-tunnel model. 


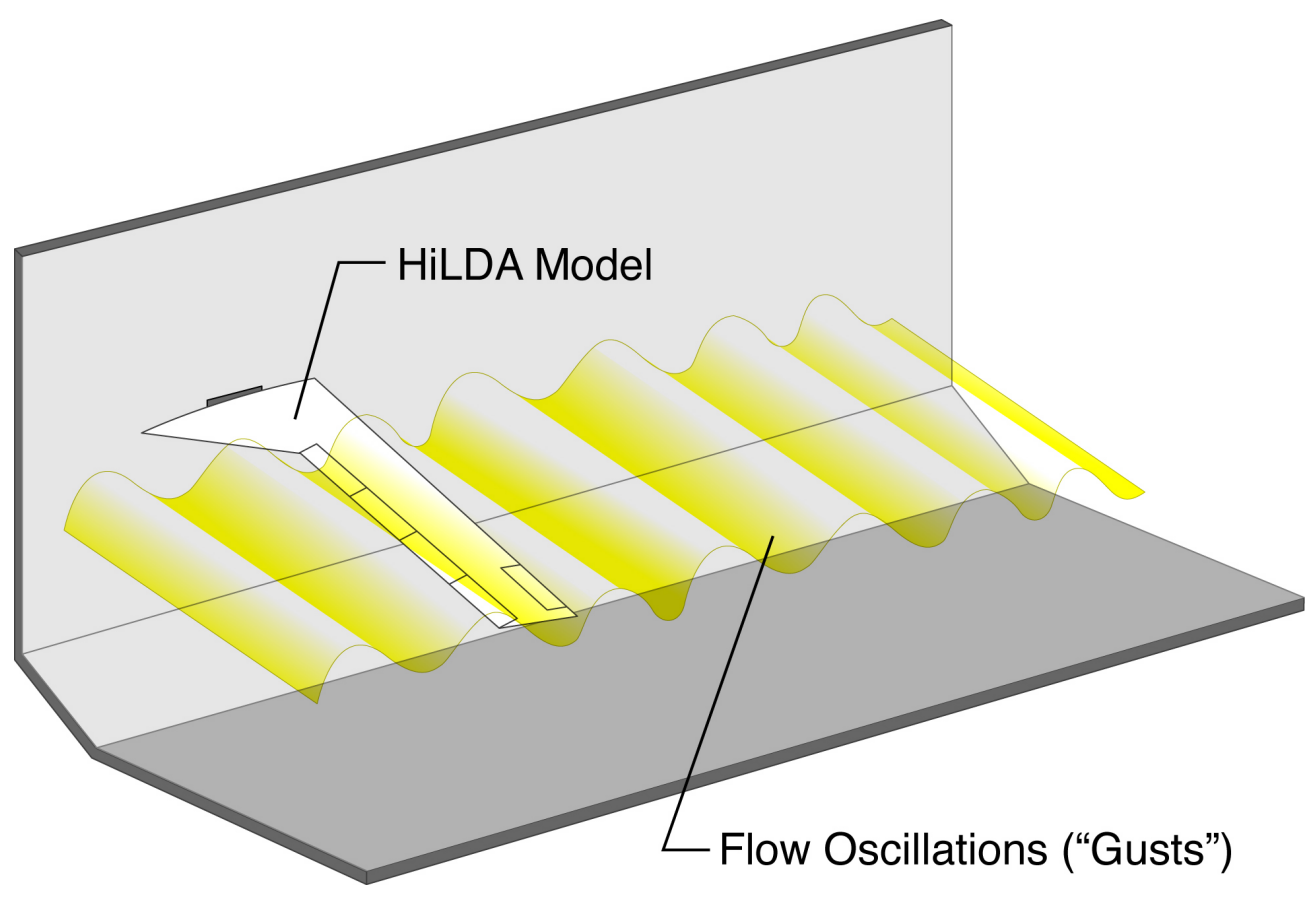

Figure 3. Schematic of the HiLDA Wing semispan wind-tunnel model and the sinusoidal gusts generated by the TDT's gust vanes

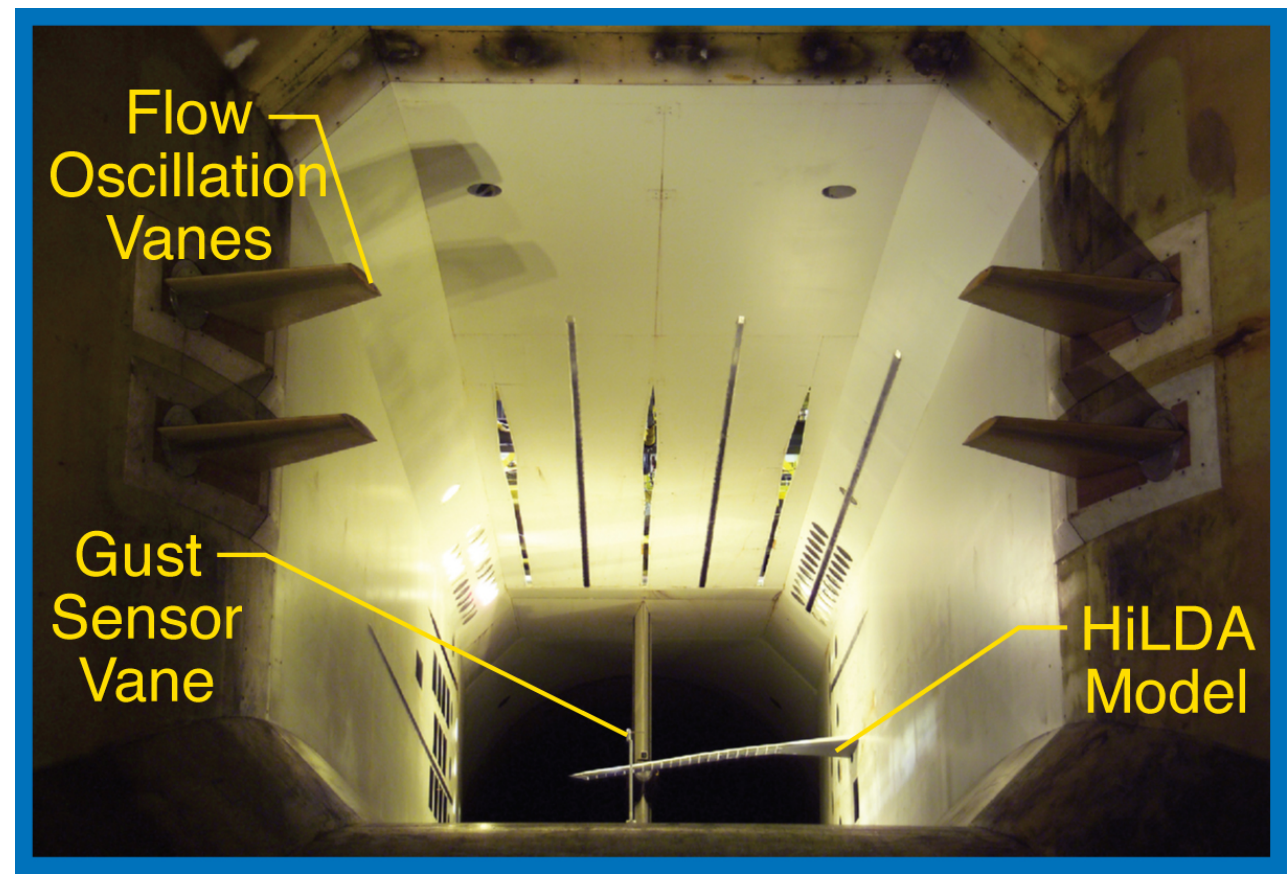

Figure 4. The HiLDA Wing model installed in the TDT and the TDT flow oscillation vanes. 


\section{Methods}

\section{Impulse Response}

The identification of aerodynamic, structural, or aeroelastic impulse responses can be performed using system identification techniques. The computational identification of unsteady aerodynamic impulse responses, for the development of efficient CFD-based models for aeroelastic analyses, has recently been performed. ${ }^{3}$ These efficient computational models, known as reduced-order models (ROMs), comprise a very active research effort at several research organizations. ${ }^{4}$ The experimental identification of unsteady aerodynamic impulse responses also has been recently reported. ${ }^{5}$ In that work, step inputs were applied to a rigid, semi-span wind-tunnel model. The unsteady pressure responses due to the step inputs were used to extract the unsteady pressure impulse responses. These impulse responses were then used to predict the unsteady pressure responses of the wind-tunnel model at several frequencies, resulting in excellent comparison with the measured responses.

For the present work, ASE analytical models for the HiLDA wind-tunnel model were generated based on measured data. During the wind-tunnel test, data was acquired that consisted of the responses of all the sensors (accelerometers, strain gauges) to frequency sweeps applied to each control surface independently. Data was also acquired for the simultaneous excitation of all the control surfaces using random inputs. The algorithms within the SOCIT ${ }^{6,7}$ (System Observer Controller Identification Toolbox), developed by Jer-nan Juang and others at NASA Langley Research Center, were used to extract impulse response functions from the measured data. A system realization technique (also within the SOCIT) was then applied to these impulse response functions in order to generate the state-space ASE analytical models. A schematic representation of the IR method is presented in Figure 5.

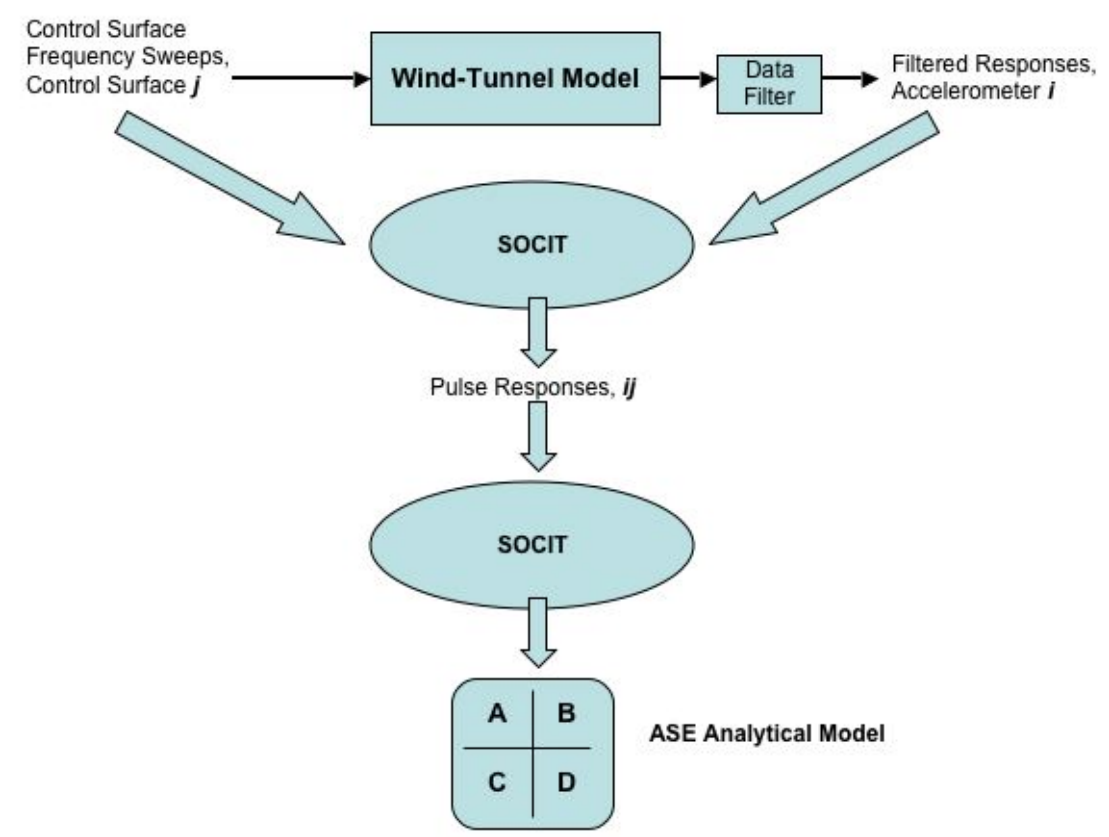

Figure 5. Flow chart describing the IR method. 


\section{Generalized Predictive Control}

Wind-tunnel tests conducted in the TDT using a 1/5-scale, semispan, aeroelastic model of the V-22 have demonstrated the potential efficacy of a predictive control method known as Generalized Predictive Control $(\mathrm{GPC})^{8}$ for actively controlling the swashplate of tiltrotor aircraft to enhance aeroelastic stability. ${ }^{9,10}$ The intention was to upgrade and extend the GPC-based software system that was developed for that model and conduct an investigation of GPC for active gust load alleviation as an adjunct to the test of the HiLDA model in the TDT. Although it was not possible to make all the necessary changes to the software in time for the subject test, appropriate data were taken during the test to allow a post-test assessment of GPC. This section of the paper presents results of some numerical simulations using this data that were made with recently-developed MATLAB programs intended to serve as the basis for the planned upgrades and extensions. Kvaternik et $\mathrm{al}^{11}$ provide a complete discussion of the various aspects of the development and application of the computational procedure. Only a brief, primarily qualitative, summary of the formulation is presented here as a prelude to the presentation of representative results from these simulations.

Generalized Predictive Control is a time-domain multi-input/multi-output predictive control method that uses an AutoRegressive with eXogenous input (ARX) model to describe the input-output relationship of the system. The coefficient matrices of the ARX equation are determined by system identification techniques. The input-output equation is used to form a multi-step output prediction equation over a finite prediction horizon. The control to be imposed at the next time step is determined by minimizing the deviation of the predicted controlled plant outputs from the desired (or target) outputs, subject to a penalty on control effort. A version of the GPC procedure was developed at Langley Research Center in 1997 for efficient computation and unknown disturbance rejection by Dr. Jer-Nan Juang and his associates. Their work resulted in a suite of MATLAB m-files that were collected into a predictive control toolbox. A summary of the theory underlying their development is found in the references. ${ }^{8,11-15}$

There are two fundamental steps involved: (1) identification of the system, and (2) use of the identified model to design a controller. Any system identification technique that returns an ARX model for the system may be used. The ARX model is then used to design the controller. During GPC implementation, system identification is done on-line, but not necessarily at every time step in the presence of the disturbances acting on the system. If all the external disturbances are unknown, the effects of the disturbance-induced output are automatically embedded in the identified ARX model and there is no need for explicit inclusion of disturbance terms in the ARX model. ${ }^{8}$ This approach leads to a controller with embedded (or implicit) feedforward. However, if any of the disturbances acting on the system are measurable, that data can be used in a feedforward path simultaneously with the feedback data to enhance closed-loop performance. In this situation, the identified ARX model includes the effects of the disturbance-induced output associated with the unknown disturbances while an AutoRegressive (AR) model identified on-line can be used to include the effects of the measurable disturbances. This approach leads to a controller with both embedded and explicit feedforward. The feedforward can be adaptive or nonadaptive.

To initiate the identification process, the system is excited with band-limited white noise in the presence of the external disturbances acting on the system. These independent random excitations are applied to the control inputs simultaneously and the responses are measured. The resulting input/output time histories are then assembled and processed as discussed by Kvaternik et al. ${ }^{11}$ The predictive control law is obtained by minimizing the deviation of the predicted controlled response from a desired response over a prediction horizon. ${ }^{11}$ A schematic representation of the GPC method is presented in Figure 6.

\section{Results Using IR Method}

Presented in Figure 7 is the power spectral density (PSD) of the frequency sweep input applied to the control surfaces with an amplitude of plus/minus one degree and a cutoff frequency of $30 \mathrm{~Hz}$.

The corresponding PSDs for two accelerometers (AS4 and AS5) due to the frequency sweep input applied to the control surfaces is presented as Figure 8. These responses, because of the fairly high frequency content, provided some challenges to the state-space model development algorithms resulting in excessively large statespace models. In order to alleviate this problem and improve the system identification process, the output signals were filtered using an 11th-order Equiripple filter with a cutoff frequency of $12 \mathrm{~Hz}$, well above the frequency range of the dominant dynamics of the wind-tunnel model. The Equiripple filter also had minimal phase lag. A comparison of the original and filtered signals for accelerometer AS4 due to TE1 (inboard-most trailing edge control surface) is presented as Figure 9. 


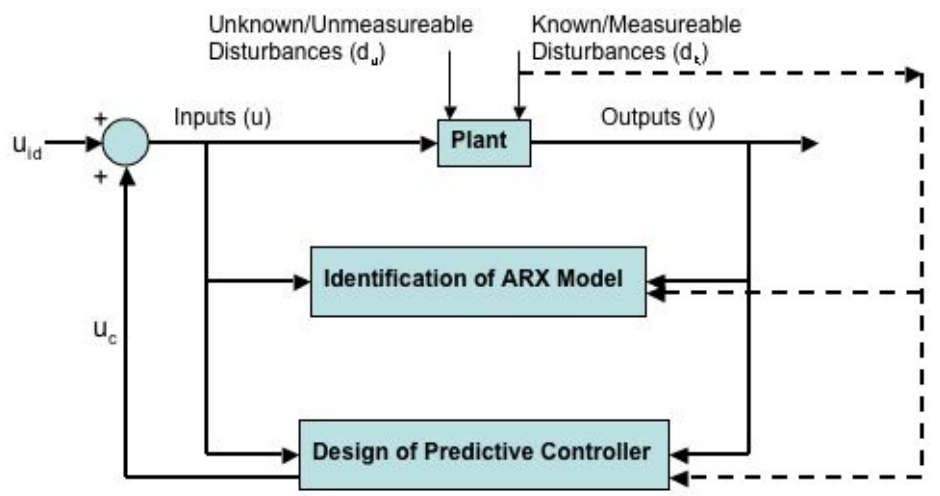

Figure 6. Flow chart describing the GPC method.

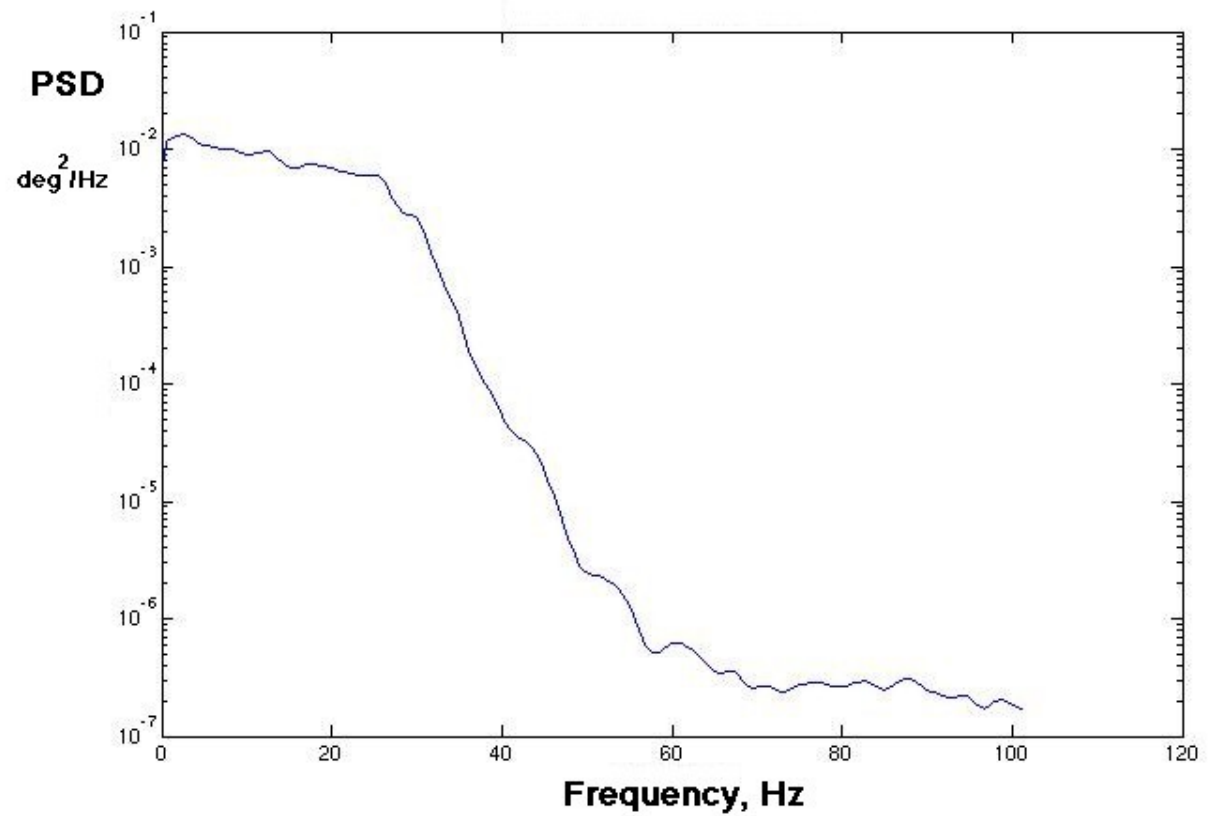

Figure 7. Power spectral density of frequency sweep applied to control surfaces. 


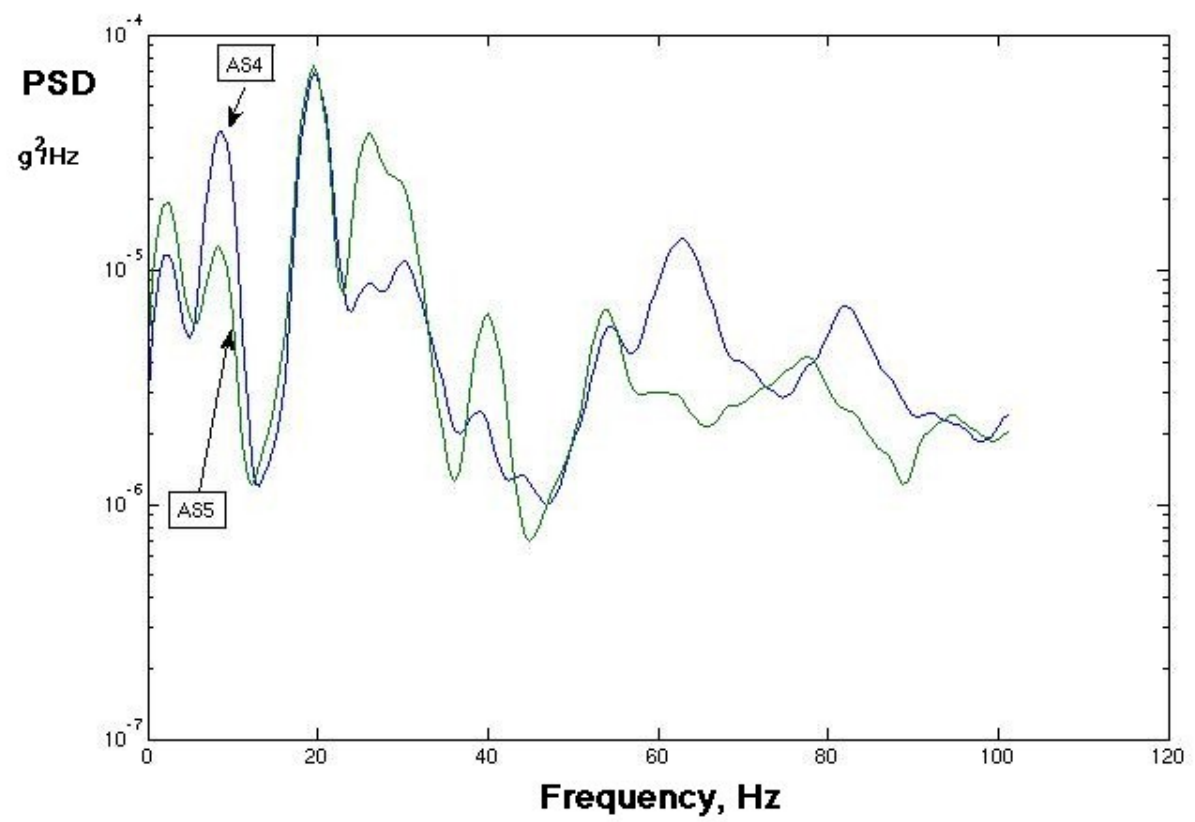

Figure 8. Power spectral density of two accelerometers due to control surface sweep excitation applied to control surface TE1.

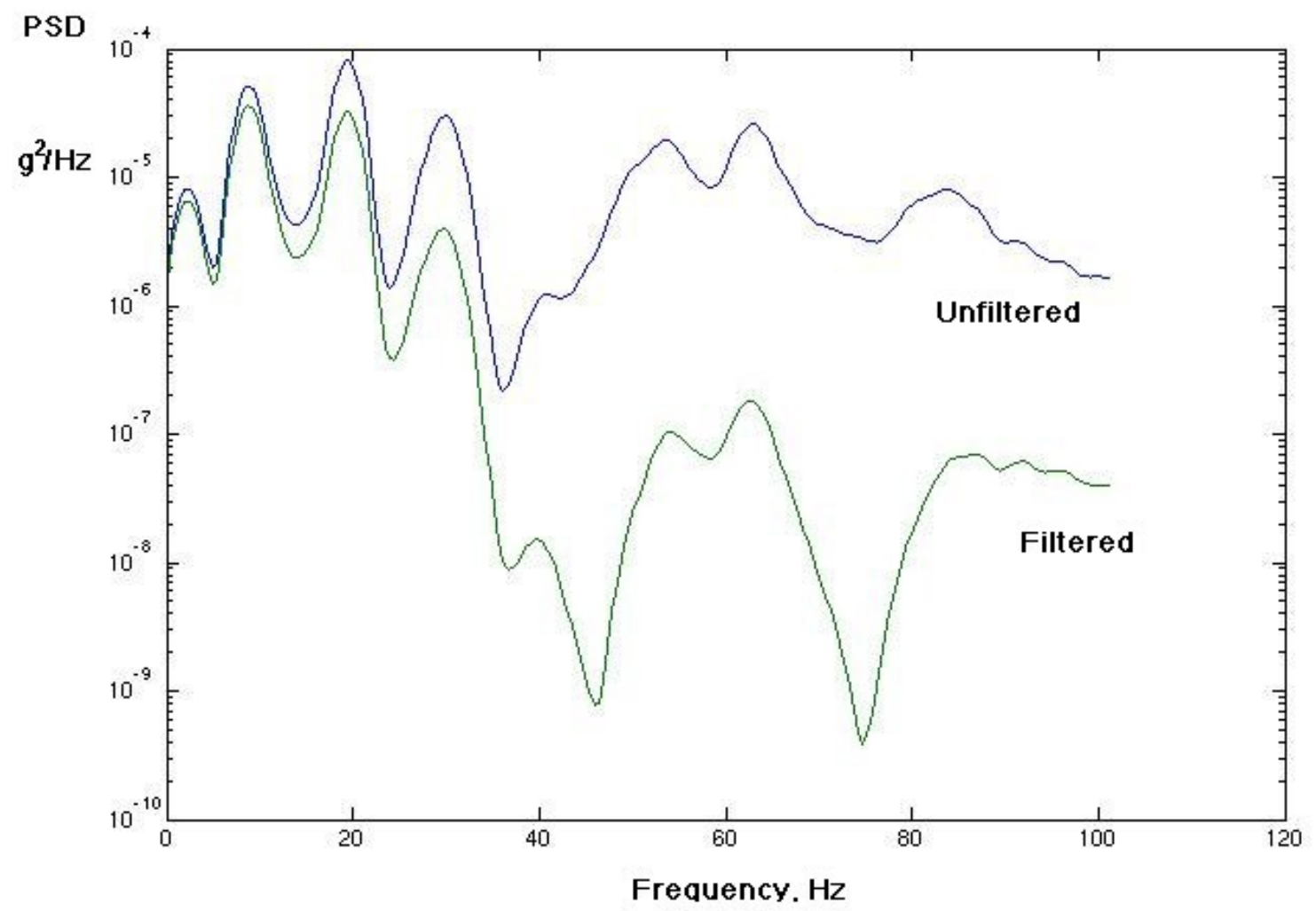

Figure 9. Comparison of filtered and unfiltered signals for AS4 accelerometer signal. 
Using the input and output data from the frequency sweeps, impulse responses for each sensor (accelerometer and strain gauge) due to each control surface were generated. These impulse responses are referred to as pulse responses in the discrete-time domain. A sample of these pulse responses are presented in Figure 10 where Pulse11 refers to the pulse response in accelerometer AS1 due to a pulse input from the inboard-most control surface, TE1. Pulse21 refers to the response of the AS2 accelerometer due to a pulse input from the TE1 control surface. The Pulseij nomenclature indicates the pulse response for the i'th sensor due to a pulse input from the j'th control surface.
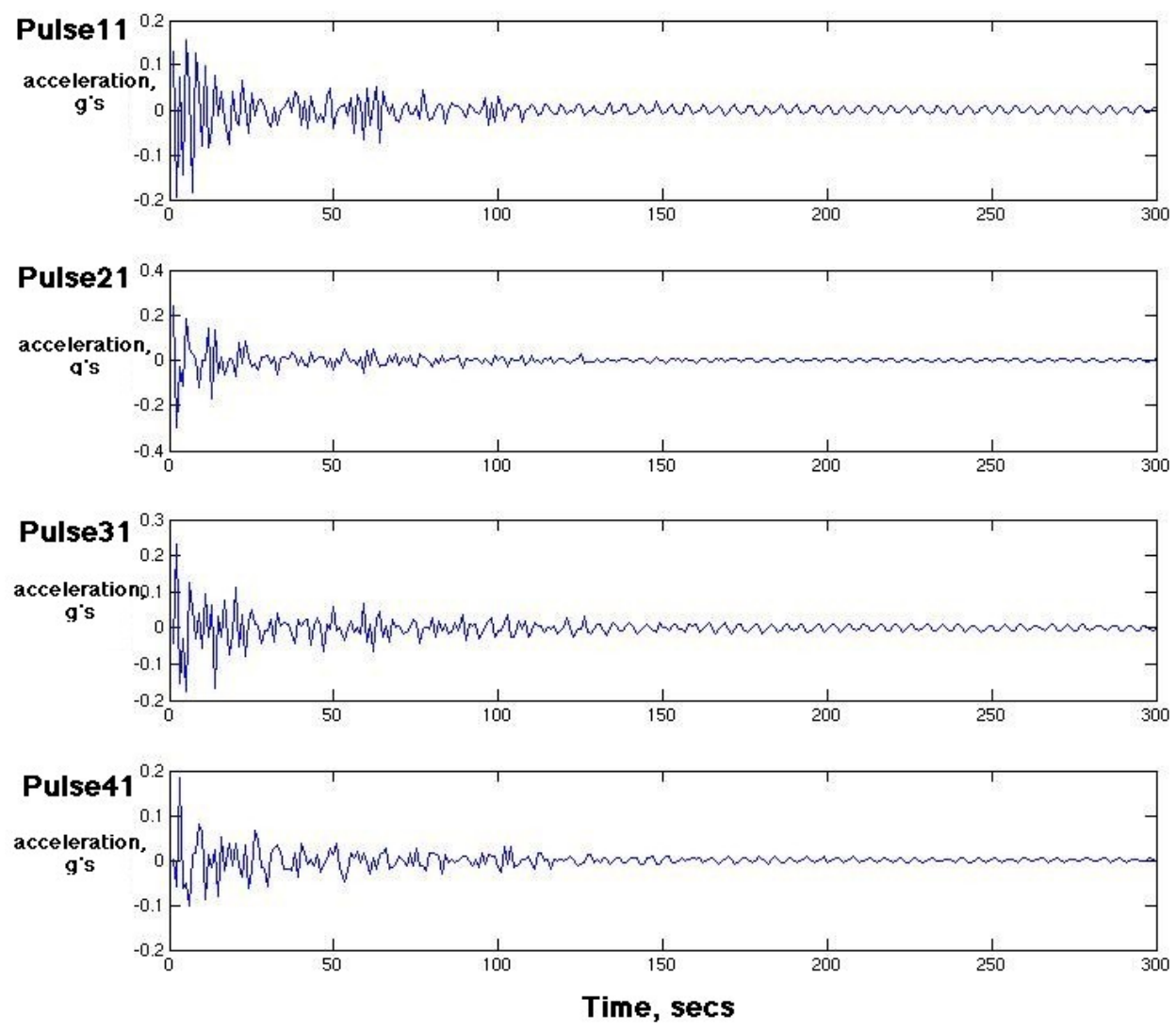

Figure 10. Pulse responses for an accelerometer identified using input (frequency sweep) and output (accelerations) due to sweep.

Using the complete set of pulses computed for each input/output pair, an ABCD matrix (system quadruple) was generated. The algorithm for generating the state-space models from pulse responses provides the user with options that will influence the order of the resultant matrices. One of these options includes the record length of the pulse responses that is to be used for the development of the state-space models. The greater the record length of the pulse responses, the greater the accuracy of the resulting state-space model across a wide range of frequencies. Even with the high-frequency filtering that was performed on the signals, this increased accuracy resulted in system matrices of a high order, but at a lower order than if the filtering had not been performed. For the present case, the entire record length of the pulse responses was used. This, length however, can be significantly reduced via improved filtering and a suitable selection of system identification parameters. The ABCD matrices generated were of the following order: A $(675 \times 675)$, B(675 $\mathrm{x} 3), \mathrm{C}(7 \times 675)$, and $\mathrm{D}(7 \times 3)$.

Figure 11 presents a comparison between the measured (wind-tunnel test) and simulated (ASE model) response of accelerometer AS1 due to input from third control surface, TE3. As can be seen, the comparison is quite good using the ASE model identified using the IR method. 


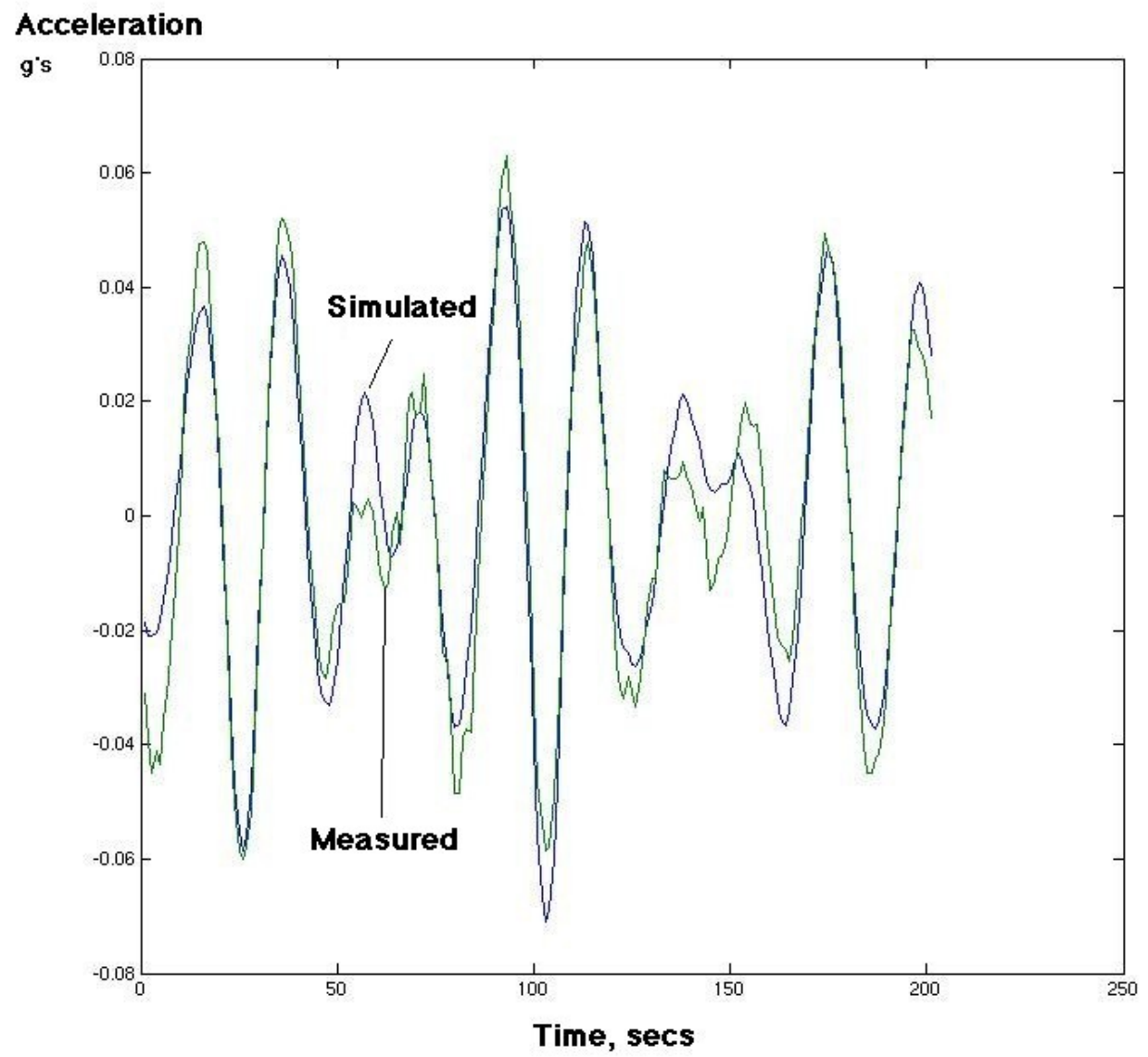

Figure 11. Measured and simulated responses of accelerometer AS1 due to input from the third control surface, TE3. 


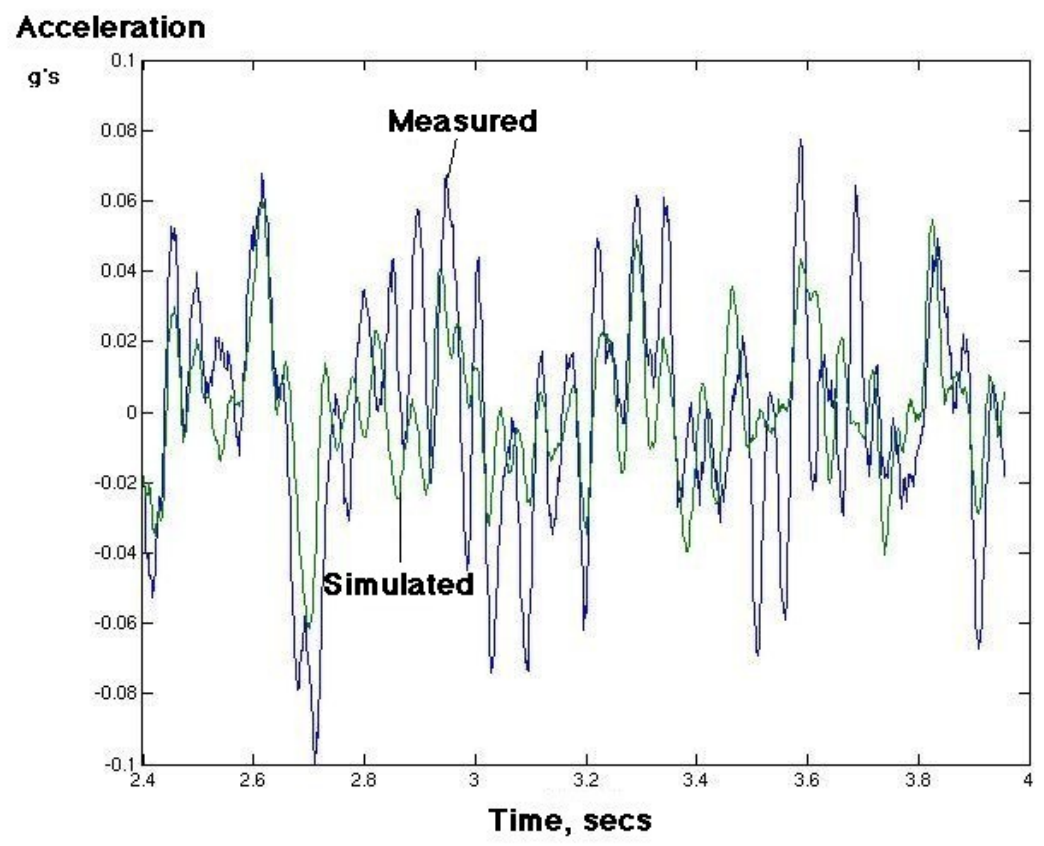

Figure 12. Time-domain comparison of measured and simulated responses for the AS5 accelerometer due to a TE4 control surface frequency sweep.

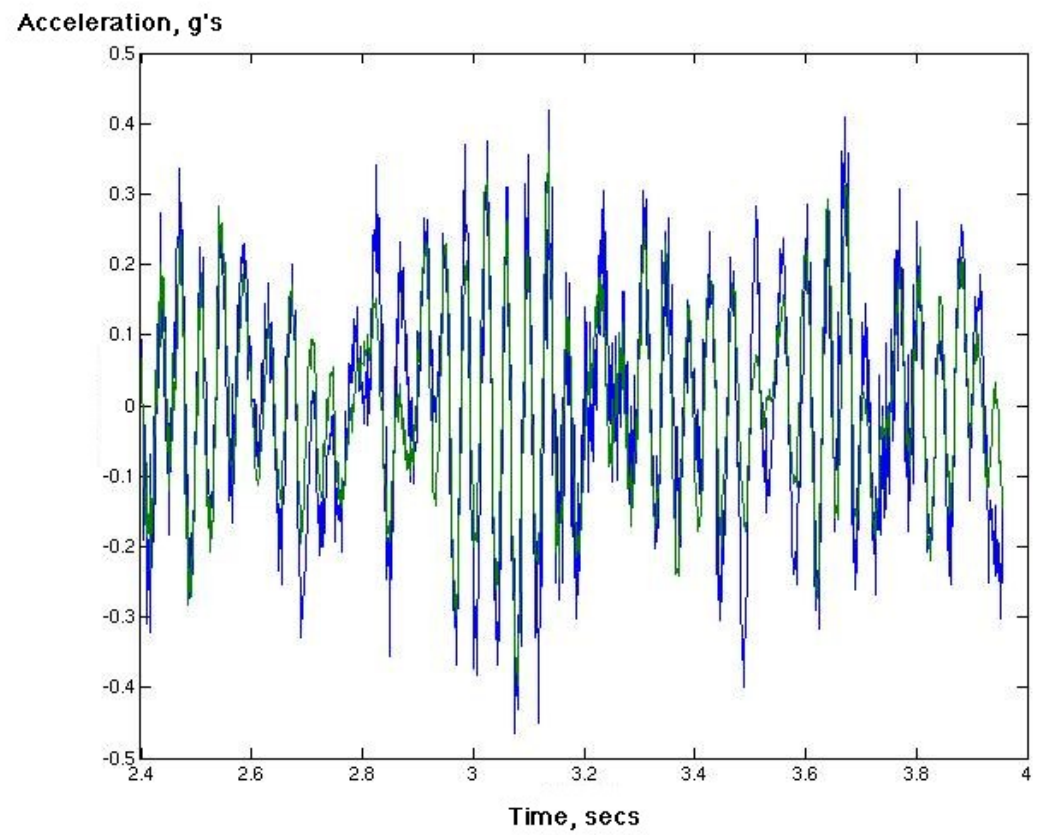

Figure 13. Time-domain comparison of measured and simulated responses for the AS7 accelerometer due to a TE4 control surface frequency sweep (Green: Simulated; Blue: Measured). 


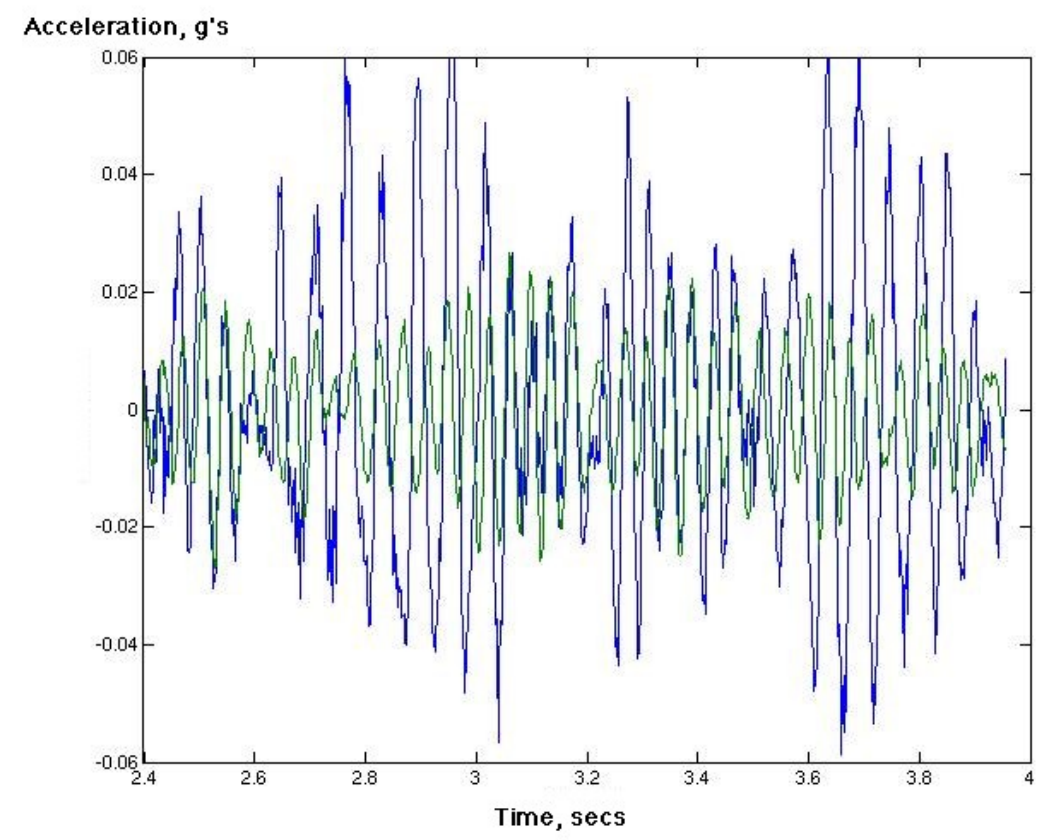

Figure 14. Time-domain comparison of measured and simulated responses for the ASY accelerometer due to a TE4 control surface frequency sweep (Green: Simulated; Blue: Measured).

In order to investigate to what extent the present method can capture the nonlinear effects associated with the coupling of the fore-aft bending mode and the out-of-plane bending mode, additional data points were investigated. The dataset analyzed consisted of a frequency sweep of TE4 at a Mach number of 0.3 and a dynamic pressure of $70 \mathrm{psf}$. The primary output of interest is the ASY (fore-aft) accelerometer measurement. Time-domain and frequency-domain results, and comparisons with experimental data, are presented below for a subset of the outputs. For these results, filtering was applied, which proved beneficial for the correlation process.

Figure 12, Figure 13, and Figure 14 are time-domain comparisons for AS5, AS7, and ASY: (blue is measured; green is simulated). The results for AS5 (Figure 12) and for AS7 (Figure 13) are similar to the results presented thus far and represent a reasonable comparison. For the ASY sensor (fore-aft), clearly some of the content is captured, but there are additional frequencies, possibly due to nonlinear interactions, that were not captured using this method. The corresponding frequency-domain plots are presented as Figure 15, Figure 16, and Figure 17 for AS5, AS7, and ASY: (blue is measured; green is simulated).

The next step in the process of evaluation of the IR method is to develop GLA control laws using the ASE models generated using the IR method. These control laws can then be compared with the control laws designed using standard linear computational methods in order to determine if a benefit is derived from using the IR method. Additional analyses are required to determine an optimal approach for capturing a greater level of potentially nonlinear interactions.

\section{Results Using GPC}

For the application of the GPC method, the measured data used in the method were obtained in heavy gas (R134a) at a dynamic pressure of 51 psf. For system identification, random excitations of all five control surfaces (four trailing edge, one leading edge) were imposed simultaneously and consisted of uncorrelated, normally-distributed random numbers with mean zero and a variance chosen to limit the oscillation angles of the control surfaces to about 2 degrees. Thirty-five seconds of data were acquired at each tunnel condition of interest at a sampling rate of $500 \mathrm{~Hz}$, giving a total of 17500 data points in each record. To exclude transients, data outside the time sample range of 1000 to 15000 were discarded. Since the primary wing modes to be controlled were less than $15 \mathrm{~Hz}$, the truncated data were decimated by a factor of ten to give an 


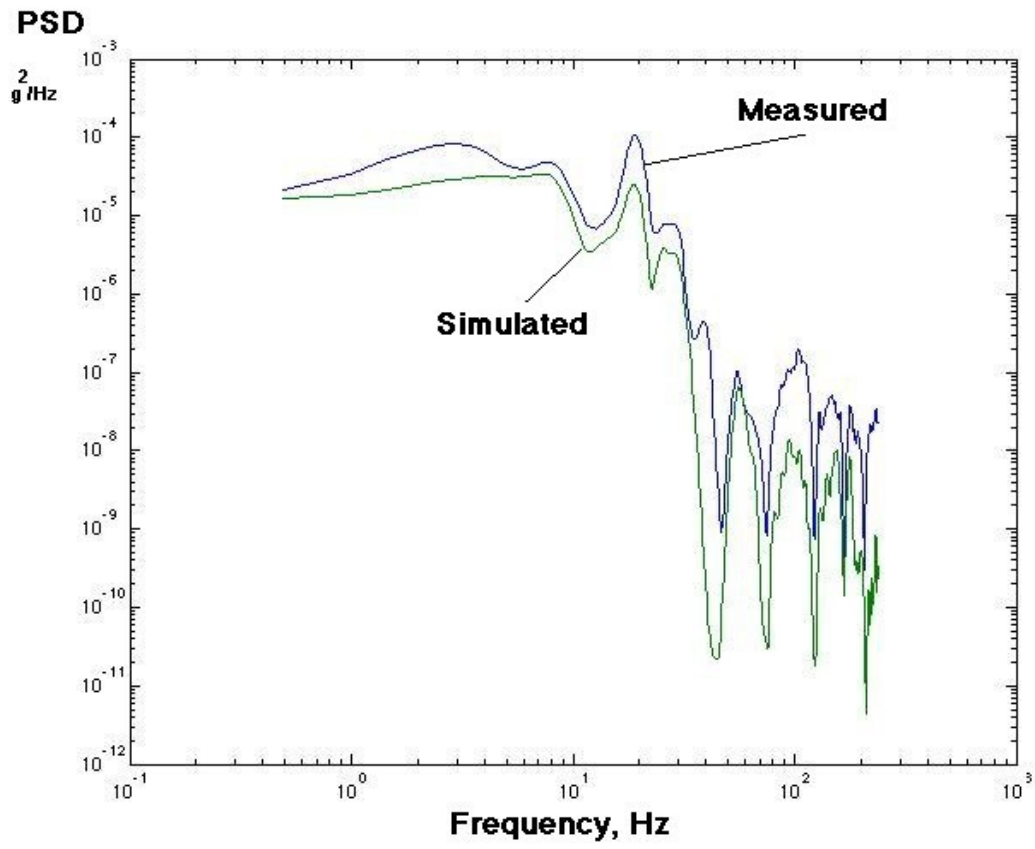

Figure 15. Frequency-domain comparison of measured and simulated responses for the AS5 accelerometer due to a TE4 control surface frequency sweep.

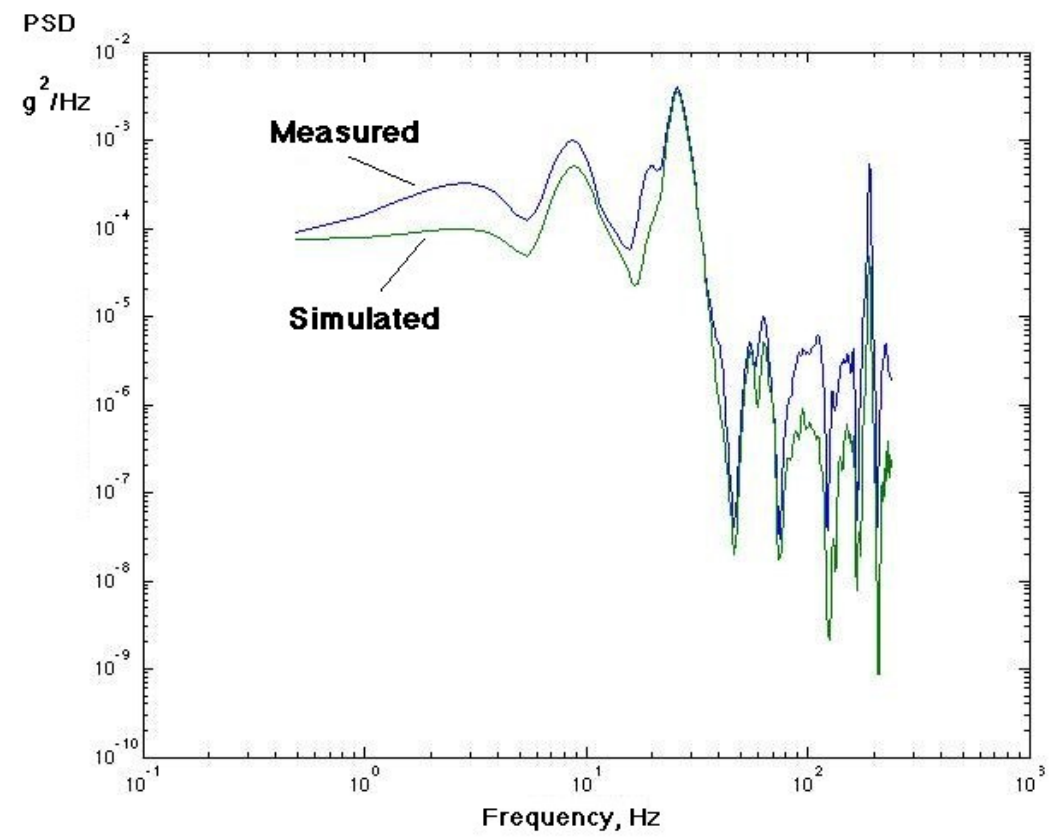

Figure 16. Frequency-domain comparison of measured and simulated responses for the AS7 accelerometer due to a TE4 control surface frequency sweep. 


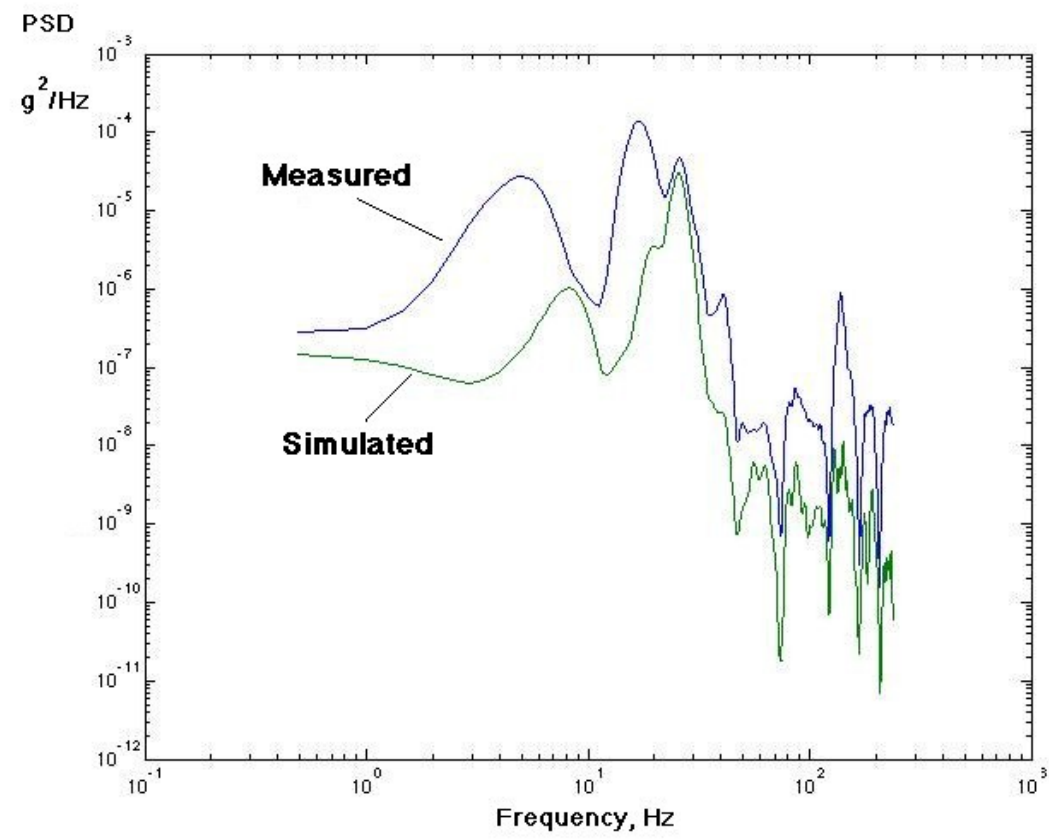

Figure 17. Frequency-domain comparison of measured and simulated responses for the ASY accelerometer due to a TE4 control surface frequency sweep.

effective sampling frequency of $50 \mathrm{~Hz}$. The mean value of each measurement was subtracted from its time history. The conditioned input-output data were used to identify the plant and to develop a GLA controller. The three outputs SBI2, SBY, and STI2 were selected as the quantities to be minimized collectively. All five control surfaces were used by the GLA control law.

The control weights were set to 0.3 . Both the prediction horizon and the control horizon were set equal to the assumed system order of 10. The feedforward signal was taken from the gust sensor vane that measured gust-induced flow angle. The loop was closed after five seconds in the simulations. Although it is known that tuning of the GPC parameters (horizons, control weights, order of ARX equation) oftentimes leads to enhanced performance, no adjustments were made in these parameters in an attempt to improve performance.

Presented in Figure 18 are simulated time histories of open- and closed-loop vertical bending moments (SBI2) during gust excitation at $2 \mathrm{~Hz}$. Presented in Figure 19 are simulated time histories of open- and closed-loop fore-and-aft bending moments (SBY) during gust excitation at $2 \mathrm{~Hz}$. These results are indicative of excellent controller performance in reducing wing root vertical and fore-aft bending moments during a gust excitation at $2 \mathrm{~Hz}$. Similar results were obtained for the torsion moment but are not presented here. There is a large reduction in all three moments almost immediately after the controller is turned on.

The next set of figures shows controller performance for a swept-frequency gust excitation. Figure 20 presents time histories of open- and closed-loop vertical bending moments (SBI2) while sweeping gust frequency from 0.5 to $10 \mathrm{~Hz}$. Figure 21 presents time histories of open- and closed-loop fore-and-aft bending moments (SBY) while sweeping gust frequency from 0.5 to $10 \mathrm{~Hz}$. In comparison to the constant-frequency gust excitation cases, controller performance during excitation by a swept-frequency gust is only fair. While all three wing moments are reduced substantially, the control angles (not shown) required are larger (plus/minus 10 degrees versus plus/minus 2 degrees) than those needed for constant-frequency gusts.

Taken as a whole, the results of the closed-loop simulations are decidedly positive. In particular, the closed-loop simulations for the wing model show significant reductions in wing root moments depending, primarily, on whether the excitation is from a constant- or swept-frequency gust. Additional wind-tunnel testing of the HiLDA wing model is planned to provide further validation of the GPC method. 


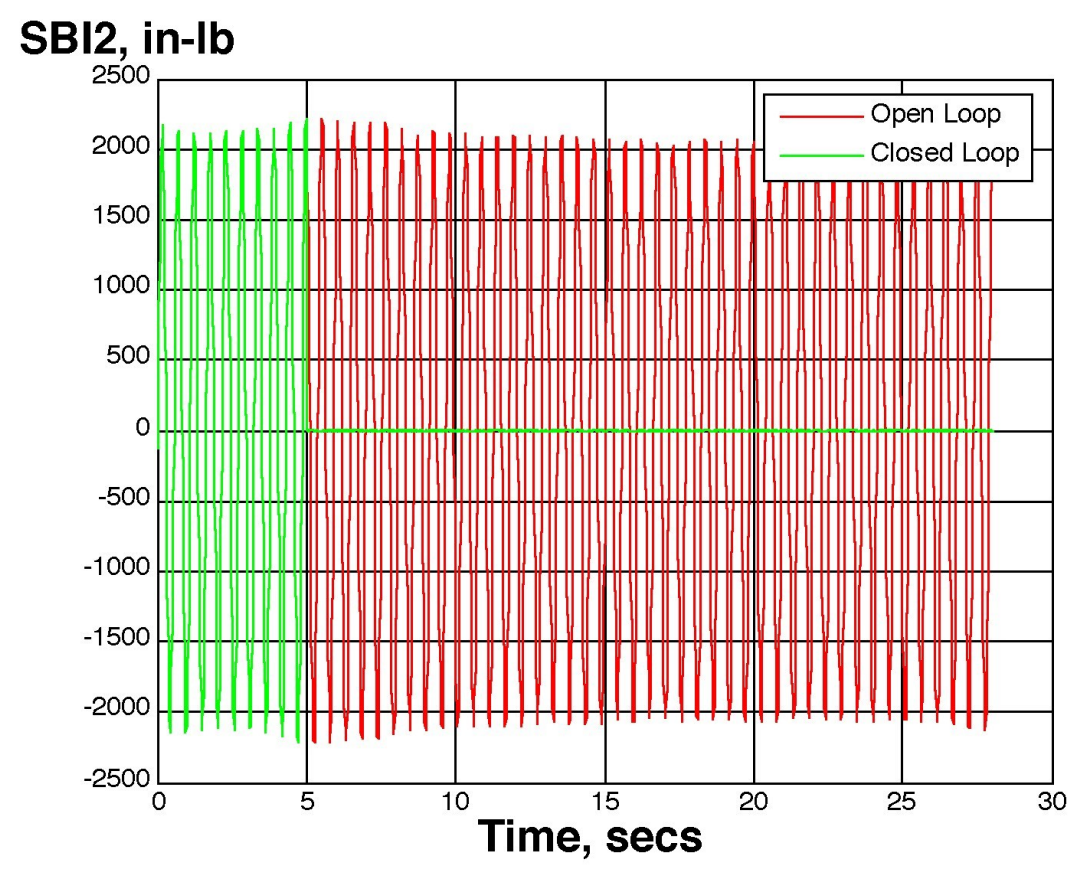

Figure 18. Simulated time histories of open- and closed-loop vertical bending moments (SBI2) during gust excitation at $2 \mathrm{~Hz}$.

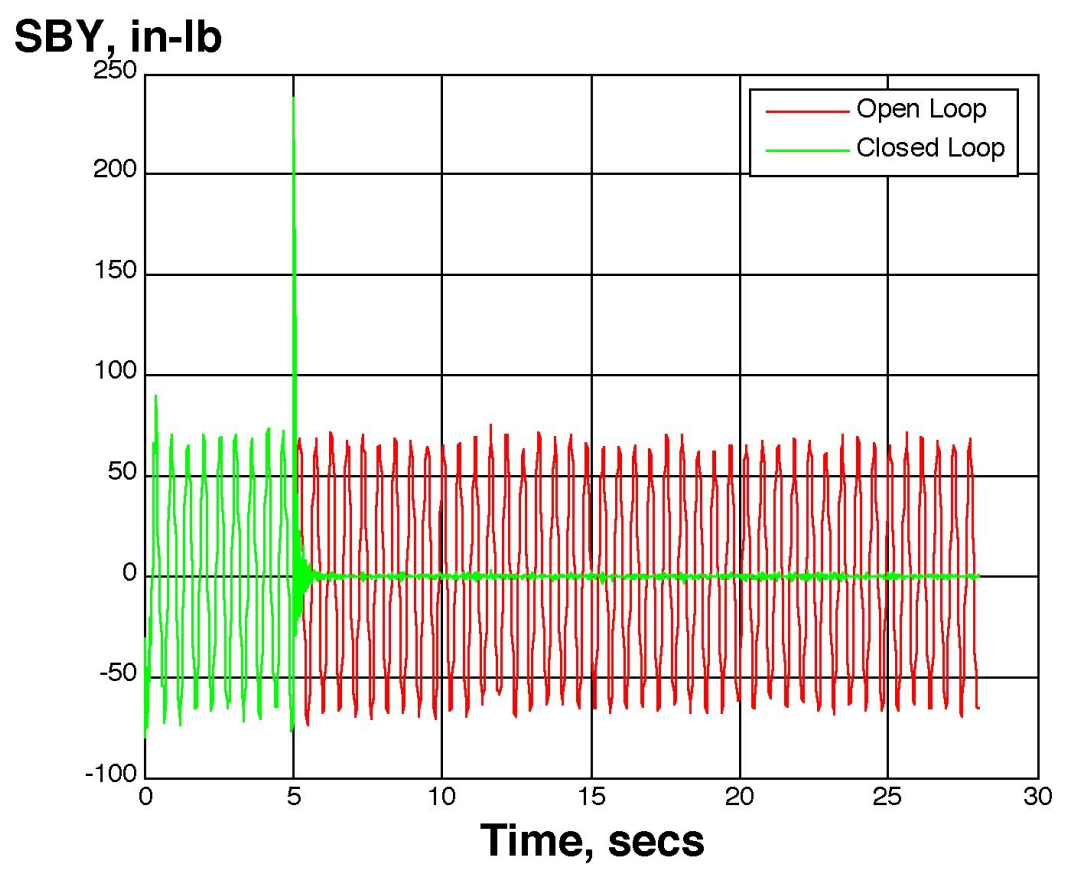

Figure 19. Simulated time histories of open- and closed-loop fore-and-aft bending moments (SBY) during gust excitation at $2 \mathrm{~Hz}$. 


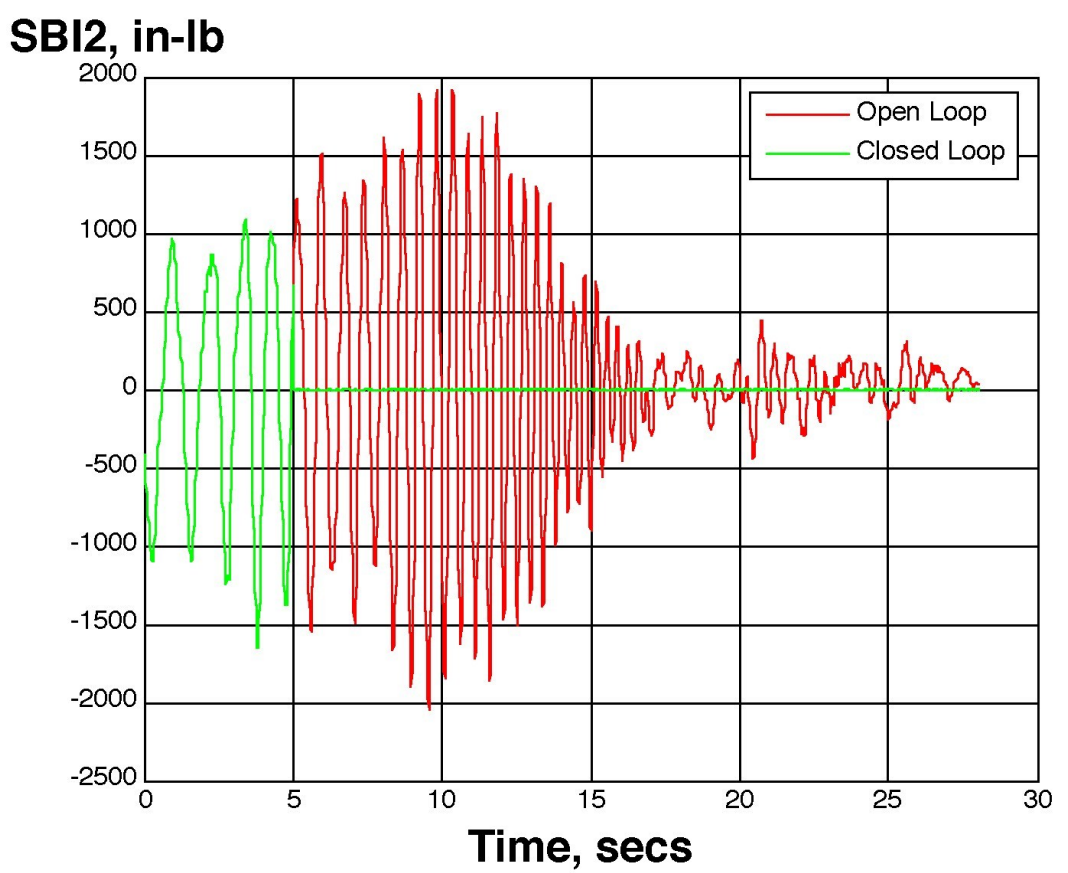

Figure 20. Simulated time histories of open- and closed-loop vertical bending moments (SBI2) while sweeping gust frequency from 0.5 to $10 \mathrm{~Hz}$.

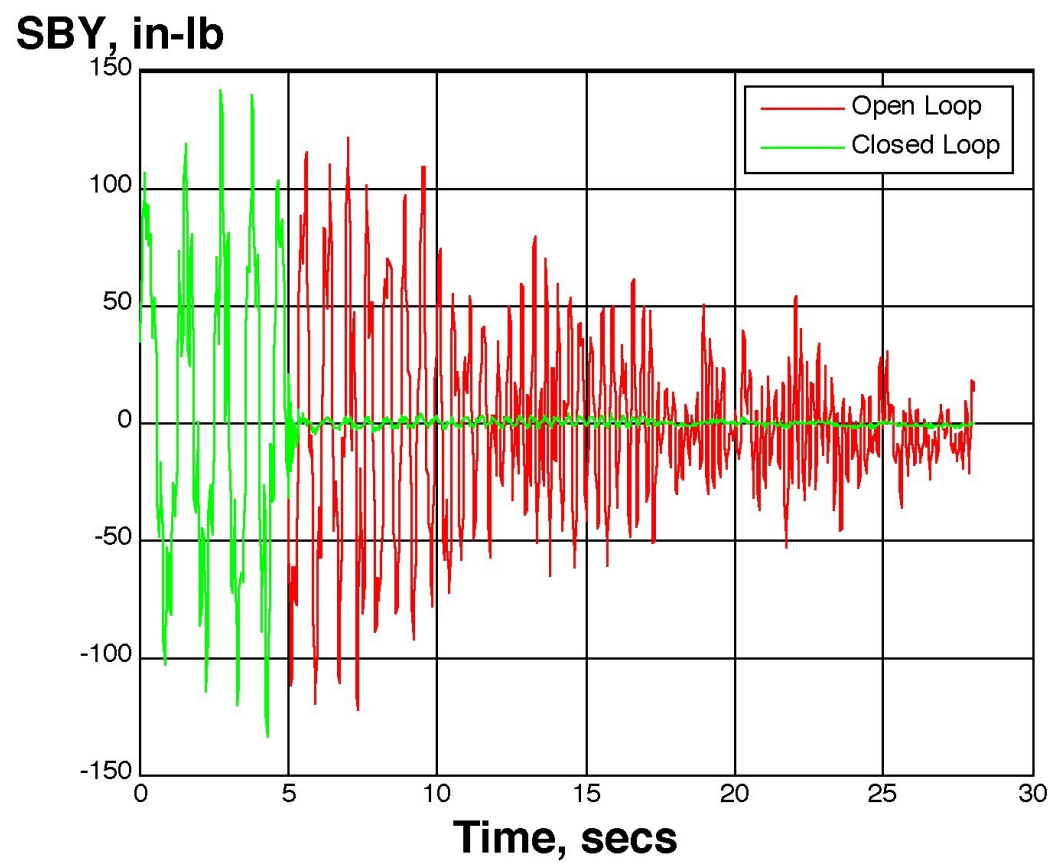

Figure 21. Simulated time histories of open- and closed-loop fore-and-aft bending moments (SBY) while sweeping gust frequency from 0.5 to $10 \mathrm{~Hz}$. 


\section{Conclusion}

The identification and generation of ASE models using experimental data and their use in generating and assessing the performance of GLA control laws has been presented. Two methods have been applied to the HiLDA (High Lift-to-Drag Active) Wing: the Impulse Response (IR) method and the Generalized Predictive Control (GPC) method. Results from the HiLDA (High Lift-to-Drag Active) Wing ASE wind-tunnel test, conducted in late 2004 at the Transonic Dynamics Tunnel (TDT), were used for comparison with the ASE models generated using the IR method. ASE models generated using the IR method indicate very good to excellent correlation with the measured data. The GPC method was used to develop an ARX model and GLA control laws. Simulated open- and closed-loop results from the GPC method indicate that the method appears to be a viable approach for GLA. Both methods will continue to be developed and investigated during the next test of the HiLDA Wing wind-tunnel model.

\section{References}

${ }^{1}$ Lucia, D. J., "The SensorCraft Configurations: A Nonlinear AeroServoElastic Challenge for Aviation," 46th AIAA/ASME/ASCE/AHS/ASC Structures, Structural Dynamics, and Materials Conference, No. AIAA-2005-1943, Austin, TX, April 2005.

${ }^{2}$ Vartio, E., Shimko, A., Tillman, C. P., and Flick, P. M., "Structural Modal Control and Gust Load Alleviation for a SensorCraft Concept," 46th AIAA/ASME/ASCE/AHS/ASC Structures, Structural Dynamics, and Materials Conference, No. AIAA-2005-1946, Austin, TX, April 2005.

${ }^{3}$ Silva, W. A. and Bartels, R. E., "Development of Reduced-Order Models for Aeroelastic Analysis and Flutter Prediction Using the CFL3Dv6.0 Code," Proceedings of the 43rd Structures, Structural Dynamics and Materials Conference, No. 02-1596, Denver, CO, April 2002.

${ }^{4}$ Beran, P. S. and Silva, W. A., "Reduced-Order Modeling: New Approaches for Computational Physics," Presented at the 39th AIAA Aerospace Sciences Meeting, 8-11 January 2001, Reno, NV, January 2001.

${ }^{5}$ Silva, W. A., Piatak, D. J., and Scott, R. C., "Identification of Experimental Unsteady Aerodynamic Impulse Responses," Journal of Aircraft, Vol. 42, Dec. 2005, pp. 1548-1552.

${ }^{6}$ Juang, J.-N. and Pappa, R. S., "An Eigensystem Realization Algorithm for Modal Parameter Identification and Model Reduction," Journal of Guidance, Control, and Dynamics, Vol. 8, 1985, pp. 620-627.

${ }^{7}$ Juang, J.-N., Phan, M., Horta, L. G., and Longman, R. W., "Identification of Observer/Kalman Filter Markov Parameters: Theory and Experiments," Journal of Guidance, Control, and Dynamics, Vol. 16, 1993, pp. 320-329.

${ }^{8}$ Juang, J.-N. and Eure, K. W., "Predictive Feedback and Feedforward Control for Systems with Unknown Disturbances," NASA TM-1998-208744, Dec. 1998.

${ }^{9}$ Kvaternik, R. G., Piatak, D. J., Nixon, M. W., Langston, C. W., Singleton, J. D., Bennett, R. L., and Brown, R. K., "An Experimental Evaluation of Generalized Predictive Control for Tiltrotor Aeroelastic Stability Augmentation in Airplane Mode of Flight," J. Amer. Hel. Soc, Vol. 27, July 2002, pp. 198-208.

${ }^{10}$ Nixon, M. W., Langston, C. W., Singleton, J. D., Piatak, D. J., Kvaternik, R. G., Corso, L. M., and Brown, R. K., "Aeroelastic Stability of a Four-Bladed Semi-Articulated Soft-Inplane Tiltrotor Model," AHS 59th Annual Forum and Technology Display, May 2003.

${ }^{11}$ Kvaternik, R. G., Eure, K. W., and Juang, J.-N., "Exploratory Studies in Generalized Predictive Control for Active Gust Load Alleviation," NASA TM-2006-214296, April 2006.

${ }^{12}$ Juang, J.-N., Applied System Identification, Prentice-Hall, Englewood Cliffs, NJ, 1994.

${ }^{13}$ Eure, K. W., "Adaptive Predictive Feedback Techniques for Vibration Control," PhD dissertation, Virginia Polytechnic Institute and State University, May 1998.

${ }^{14}$ Phan, M. Q. and Juang, J.-N., "Predictive Controllers for Feedback Stabilization," Journal of Guidance, Control, and Dynamics, Vol. 21, Sept. 1998, pp. 747-753.

${ }^{15}$ Phan, M. Q. and Juang, J.-N., "Predictive Feedback Controllers for Stabilization of Linear Multivariable Systems," AIAA Guidance, Navigation and Control Conference, No. 3769, San Diego, CA, July 1996. 